\title{
O PRÉ-VESTIBULAR SOCIAL: DESAFIOS À BUSCA DA INCLUSÃO SOCIAL
}

\author{
Maria D. F. Bastos | mariabastos2008@gmail.com \\ Doutora em Serviço Social pela Pontifícia Universidade Católica de São Paulo - PUC-SP. Professora aposentada da Escola de \\ Serviço Social da UFRJ, Diretora do Pré-Vestibular Social da Fundação CECIERJ.
}

Maria de Fátima C. M. Gomes | fcmgomes@gmail.com

Doutora em Serviço Social pela Pontifícia Universidade Católica de São Paulo - PUC-SP. Professora Titular da Escola de Serviço Social da Universidade Federal do Rio de Janeiro - UFRJ.

Lenise Lima Fernandes | leniself@uol.com.br Doutora em Planejamento Urbano e Regional pelo Instituto de Pesquisa e Planejamento Urbano e Regional - IPPUR da Universidade Federal do Rio de Janeiro - UFRJ. Professora Adjunta da Escola de Serviço Social - UFRJ.

\section{Resumo}

O artigo analisa a contribuição do Programa Pré-Vestibular Social (PVS), inserido na Fundação CECIERJ - Centro de Ciências e Educação Superior a Distância do Estado do Rio de Janeiro, no enfrentamento de algumas barreiras de acesso ao Ensino Superior nesse estado. Diversas expressões de exclusão/inclusão são utilizadas como fio condutor da análise, partindo-se do princípio de que o desenvolvimento de ações educativas complementares e as informações são fundamentais para favorecer o acesso de estudantes de baixa renda a instituições de Ensino Superior, em especial nas universidades públicas, que historicamente têm sido elitizadas, sobretudo nos bacharelados formadores de profissionais liberais. Para este estudo, foi feita uma revisão da literatura sobre o tema, especialmente sobre a questão da exclusão, bem como foram utilizadas matérias em jornais, sites da internet, dados estatísticos produzidos pelo PVS e por órgãos de pesquisa especializados. O trabalho demonstra a relevância do programa e de seus resultados, embora aponte algumas alternativas para a sua expansão e melhoria tais como: a ampliação de polos em diferentes municípios e a melhoria da infraestrutura nos já existentes, o aperfeiçoamento de professores através da criação de estratégias/incentivos que garantam a qualidade do curso, a capacitação tanto de alunos como de professores na área de informática, a implementação da disciplina de língua estrangeira (inglês) com metodologia EAD, a ampliação do leque de alternativas culturais aos alunos e professores. Finalmente, destaca-se como desafio a inclusão de alunos de baixa renda, deficientes visuais e auditivos.

\section{Palavras-chave}

Pré-Vestibular Social. Inclusão/exclusão social. Acesso à universidade. Ensino a distância. 


\section{Abstract}

The article analyzes the contribution of the Pre- Vestibular Social (PVS), inserted in CECIERJ Foundation - Center for Science and Higher Distance Education in the State of Rio de Janeiro, in confronting some barriers to higher education in that State. Several expressions of exclusion and inclusion are used as a guideline for analysis, starting from the principle that the development of additional educational and information are essential to improve access for low-income students to higher education institutions, especially in public universities which historically have been made elitist, especially in the bachelor of professional trainers. For this study we made a review of the literature on the subject, especially on the issue of exclusion and materials were used in newspapers, websites, statistics produced by the PVS and specialized research institutions. The work demonstrates the relevance of the program and its results, but suggests some alternatives for expansion and improvement such as: the expansion of poles in different cities and the improvement of the existing infrastructure, improvement of teachers through the creation of strategies / incentives to ensure the quality of the course, training for pupils and teachers in computer applications, the implementation of the discipline of foreign language (English) at Distance Learning Methodology, a wider range of cultural alternatives to students and teachers. Finally, we point the challenge the inclusion of low-income students visually and hearing impaired.

\section{Keywords}

Pré-Vestibular Social, Exclusion/inclusion, Access to university, Distance learning

\section{Introdução}

$\mathrm{O}$ direito de todos à educação deve ser considerado princípio básico em sociedades democráticas. No Brasil, a Constituição Federal (1988) e a Lei de Diretrizes e Bases da Educação Nacional (1996) ressaltam a promoção da inclusão educacional como elemento componente da nacionalidade, reconhecendo-a como direito de todos, independentemente de etnia, gênero, idade, condições econômicas, sociais, físicas e mentais.

De acordo com um estudo recentemente divulgado pelo IPEA (CASTRO et alii, 2009), com base nas informações da Pesquisa Nacional por Amostra de Domicílios (PNAD) de 2007, a população brasileira de jovens entre 15 e 29 anos alcançava cerca de 49,8 milhões de pessoas, correspondendo a $26,5 \%$ da população total. Destes, 29,8\% podiam ser considerados pobres, pois apresentavam renda familiar per capita de até meio salário mínimo. Dos jovens de 15 a 17 anos, somente 47,9\% estavam cursando o Ensino Médio, etapa adequada para essa faixa etária, e apenas $13 \%$ dos jovens de 18 a 24 anos frequentavam o Ensino Superior em 2007.

Tendo em vista o número insignificante de jovens inseridos nas universidades públicas, a Andifes (Associação Nacional de Dirigentes das Instituições de Ensino Superior), conforme afirma Duarte Filho (2009), considera inadiável e relevante uma política pública que estabeleça metas de inclusão. Por outro lado, entende que há necessidade de não reduzir as estratégias e instrumentos de inclusão a uma única modalidade. Essa necessidade tem sido intensamente discutida por diversos segmentos da sociedade brasileira, delineando um debate profuso e polêmico no que tange às distintas orientações políticas que sustentam as medidas a serem tomadas com tal objetivo e no que se refere às dinâmicas que devem ser adotadas para a sua efetivação.

Apesar dos recentes investimentos destinados à ampliação do acesso ao Ensino Fundamental e Médio em nosso país, esse esforço não foi acompanhado pela melhoria de qualidade desses cursos na rede pública. Além disso, problemas diversos refletem na dinâmica de transição do Ensino Médio ao Superior, criando historicamente obstáculos reais para grande parcela 
da população quanto às suas possibilidades de aprimoramento educacional e de mobilidade socioeconômica por meio da formação universitária.

Partindo dessa visão, este artigo analisa a contribuição do Programa Pré-Vestibular Social (PVS) no enfrentamento de algumas das diversas barreiras de acesso ao Ensino Superior no estado do Rio de Janeiro.

O Programa teve início em agosto de 2003 numa iniciativa do Governo do Estado viabilizada pela Secretaria de Ciência, Tecnologia e Inovação e da Fundação CECIERJ (Centro de Ciências e Educação Superior a Distância do Estado do Rio de Janeiro), órgão gestor do Consórcio CEDERJ (Centro de Ensino Superior a Distância do Estado do Rio de Janeiro). ${ }^{1}$ Esse Consórcio reúne as seis universidades públicas sediadas no estado - UFRJ, UERJ, UFF, UNIRIO, UFRRJ e UENF - em função do reconhecimento de uma necessidade social inquestionável, que atinge especialmente as camadas pobres do interior do estado que apresentaram dificuldades mais marcantes para a aprovação em seus vestibulares à época do lançamento do CEDERJ.

Dados da PNAD realizada pelo IBGE em 2002 indicam que $38 \%$ dos alunos em universidades públicas são provenientes de famílias com renda per capita inferior a dois salários mínimos, enquanto nas universidades privadas essa faixa de renda abrange apenas $24 \%$ dos alunos. Além disso, na faixa abaixo de um salário mínimo, a incidência na universidade pública é mais que duas vezes maior do que nas instituições privadas. Tais dados levaram Brito Cruz (2004), ex-reitor da Unicamp, a escrever um artigo intitulado "Universidade pública - o mito do elitismo", afirmando que a universidade pública é inclusiva, por abranger parcelas importantes da população de baixa renda $e$ por incorporar maior diversidade étnica. O embate de Brito Cruz era com setores do Ministério da Fazenda à época, que, segundo ele, acusando a universidade pública de servir aos "10\% mais ricos", propunham a diminuição das verbas e a extinção do Ensino Superior gratuito, pretendendo assim "debitar à universidade pública o ônus da desigualdade educacional".

De acordo com dados divulgados pela Comissão de Vestibular da UFRJ (2010), no vestibular 2007, na faixa de renda acima de trinta salários mínimos para cada cinco inscritos, um foi aprova- do, enquanto na faixa de renda de até um salário mínimo, entre cada dezenove inscritos, apenas um conseguiu aprovação. José Murilo de Carvalho e Monica Grin (2004), usando dados do Inep/ENC 2003, mostram que 38\% dos formados em Medicina nesse ano no país pertencem à faixa de renda de mais de 20 salários mínimos, enquanto apenas $7 \%$ estão na faixa de renda de até três salários mínimos. Os autores observam também que, nas licenciaturas, por exemplo, os dados se invertem, na medida em que há maior percentual de alunos pertencentes aos segmentos de mais baixa renda no país. Assim, afirmam,

é necessário distinguir sempre o curso de que se está falando. Pode-se dizer mesmo que o problema não é tanto entrar na universidade pública, mas entrar nos cursos de elite do bacharelado (CARVALHO; GRIN, 2004, p. 20).

Portanto, trata-se na realidade de verificar o que de fato ocorre no gargalo em que se constituem as provas dos vestibulares, ou seja, quais são as chances de integrantes da população de baixa renda ultrapassarem essas barreiras, sobretudo nos cursos formadores de profissionais liberais, como Medicina, Direito, Engenharia, Odontologia e Arquitetura.

Não se pode negar a relevância das discrepâncias qualitativas entre o ensino privado e o público, especialmente no Fundamental e no Médio. De acordo com a avaliação dos resultados do Enem divulgados pelo Inep (2006), alunos que estudaram somente em escola pública obtiveram médias 34,94 (prova objetiva) e 51,23 (redação), enquanto o grupo que declarou ter estudado somente em escola particular teve média 50,57 na parte objetiva e 59,77 na redação.

Os índices apresentados sugerem que famílias de maior poder aquisitivo podem propiciar aos filhos ensino de melhor qualidade, complementando-o com cursos pré-vestibulares caso julguem tal reforço pertinente para enfrentar a intensa disputa na admissão ao Ensino Superior. Esse quadro torna-se, pois, forte indicador da necessidade de reforço acadêmico dos alunos de camadas menos favorecidas da população, justificando a utilização de verbas públicas num programa de inclusão social, como é o Pré-Vestibular Social do Cecierj. 
Do nosso ponto de vista, a proposta de democratização do acesso à Educação Superior deve buscar medidas que corrijam as distorções do sistema educacional em seus mecanismos centrais vigentes. Assim, por coerência, tal proposta deve pautar-se em medidas não restritivas. Não se trata, então, de simplesmente garantir vagas para os "excluídos", através, por exemplo, de uma política de cotas, cujo debate tem tomado consistência através da adoção de medidas por parte de instituições públicas de Ensino Superior. Entendemos que estratégias e instrumentos de inclusão podem ser múltiplos, mas devem buscar garantir a reversão das contradições e das condições de desigualdade observadas nessa área da dinâmica social. Entre outras medidas, deve-se elevar a qualidade do ensino público nos níveis Fundamental e Médio e elaborar programas que possam suprir as defasagens deixadas nos que já concluíram esses segmentos da formação escolar.

O Programa Pré-Vestibular Social é entendido aqui, portanto, como um passo na direção de oferecer alternativas concretas aos alunos que, ao longo do Ensino Fundamental e Médio, não tiveram oportunidade de desenvolver suas capacidades de aprendizagem nos padrões hoje exigidos para garantir seu ingresso no Ensino Superior, seja pela baixa qualidade da instrução recebida, seja por inúmeros outros percalços que os segmentos mais pobres da população enfrentam para desenvolver continuadamente sua escolarização. Sensível a essa realidade, o Pré-Vestibular Social configurouse como um curso com público-alvo composto por pessoas que já concluíram ou que estão frequentando o último ano do Ensino Médio e desejam ter suporte para concorrer a vagas no Ensino Superior em concursos vestibulares.

Para desenvolver a análise aqui proposta, buscaremos sinteticamente recuperar alguns elementos do debate sobre inclusão/exclusão social e suas expressões empíricas na realidade educacional brasileira para, em seguida, apresentar breve histórico da experiência do Pré-Vestibular Social. Finalmente teceremos algumas considerações gerais no intuito de colocar em perspectiva o trabalho que vem sendo desenvolvido a partir dessa experiência.

\section{Exclusão/Inclusão}

Compartilhando as análises propostas por Martins (1997) e Oliveira (2003), vamos tratar as desigualdades observadas na sociedade brasileira como materializações das contradições inerentes ao modo de produção capitalista, considerando suas especificidades na dinâmica social do país e seus "novos" contornos na fase atual da globalização da economia.

Nesse sentido, entendemos que os diversos problemas relacionados aos obstáculos hoje encontrados para efetivar a democratização do acesso à educação formal no Brasil apresentam-se como expressões de processos e situações simultâneas de inclusão/exclusão. Isso significa tomar tais processos na amplitude de condições sempre relativas, geradas pela distribuição desigual da riqueza (material e imaterial), ao abrigo das regras do capitalismo.

Por essas razões, na discussão sobre nosso objeto de análise, devemos considerar tanto as alterações recentes observadas na sociedade brasileira no contexto da globalização econômica e suas inflexões no sistema educacional quanto a posição que nela ocupam os segmentos de menor poder aquisitivo de nossa população e que normalmente compõem o perfil dos usuários do Pré-Vestibular Social e de outros programas comunitários de natureza semelhante.

Diversos autores têm buscado avaliar os impactos da globalização na dinâmica do sistema educacional brasileiro. Entre os aspectos debatidos, enfocam-se os novos desafios à capacitação e à educação da força de trabalho nesse contexto, a partir das novas necessidades de organização, gestão e exploração da mão de obra disponível. O trabalho fragmentado, especializado e a qualificação predominantemente técnica que o acompanhava na fase do taylorismo/fordismo tendem a ser deixados em segundo plano, na medida em que o enfoque trazido pela dinâmica produtiva articulada à globalização da economia passa a demandar um trabalhador versátil, capaz de realizar muitas tarefas simultaneamente ou em um quadro de permanente alternância. Ainda assim, conforme Kuenzer (2005), tais alterações não trazem necessariamente a garantia da superação da alienação produzida no processo de trabalho, tanto na forma anterior quanto na atual. Por outro lado, entre os reflexos que esse processo traz à 
área educacional, encontra-se a exigência de formação continuada e rigorosa, com maior valorização do trabalho intelectual e das capacidades inovadoras $e$ integradoras que ele permite.

Analisando os processos que perpassam a relação entre a globalização $e$ as mudanças recentemente observadas na política educacional brasileira, Neves et alii (2007) ressaltam que a busca constante por conhecimento configurou-se como novo signo desse contexto, viabilizado e aprofundado pelas novas tecnologias de comunicação e informação. Nesse sentido, o nível de desenvolvimento educacional de um país - entre outros, mas não menos que outros - interfere significativamente no tipo de inserção que ele poderá garantir no mundo globalizado. Há, assim, "enorme revalorização do conhecimento como fonte de orientação do progresso da sociedade" (idem, p. 3).

As considerações até aqui apresentadas nos parecem fundamentais para melhor compreensão de certas mudanças observadas nas diretrizes da política de educação no Brasil a partir dos anos de 1990, assim como para que possamos avaliar o significado de iniciativas como a do Pré-Vestibular Social numa perspectiva mais ampla.

Ainda segundo Neves et alii (2007), no período da ditadura militar observou-se o estímulo à expansão da rede de ensino privada, em detrimento do ensino público e gratuito. Apesar disso, o Ensino Superior público continuou mantendo seu destaque pela qualidade da formação oferecida. No que tangia aos níveis de Ensino Fundamental e Médio, no entanto, as condições qualitativas eram diversas. A desatenção dispensada a esses segmentos pelas políticas públicas, no mesmo período, favoreceu a valorização das instituições privadas de educação, reproduzindo as expressões das desigualdades socioeconômicas constatadas no país no perfil de acesso a este serviço. Em função da elevada concorrência, o ingresso no Ensino Superior em instituição pública se tornou mais favorável à população de maior poder aquisitivo, que dispunha de educação mais qualificada, geralmente adquirida nas escolas particulares.

Os efeitos das desigualdades entre a qualidade do ensino oferecido pela rede pública e pela rede privada foram certamente amplificados pelas diferenças socio- econômicas que caracterizam o perfil da população que cada uma atende. São enormes e diversificados os obstáculos enfrentados pelos segmentos de menor poder aquisitivo, tanto para promover a inserção de suas crianças e jovens na escola quanto para garantir seu vínculo continuado a ela. Isso acarreta o aprofundamento da hierarquização do direito efetivo à educação formal, comprovando que, no capitalismo, a igualdade não é igual para todos.

Alguns índices registrados ao final da década de 1990 demonstram a complexidade das expressões da questão social na esfera da educação no país. Apoiados em fontes da PNAD/IBGE (2004), Neves et alii (2007) destacam que, ao fim dos anos de 1990, o acesso ao Ensino Fundamental era garantido a 96,8\% da população. No entanto, a taxa média de anos de estudo entre a população em idade ativa (6,52 anos) ainda é inferior àquela legalmente indicada como obrigatória (8 anos). Além disso, a queda na proporção de jovens que cursam o Ensino Médio, ${ }^{2}$ se comparada à taxa de acesso ao Ensino Fundamental, indica a descontinuidade $e$ o atraso no processo de formação escolar da população. Porém, em 2007, segundo o estudo do Ipea (CASTRO et alii, 2009), houve no Brasil avanço nas taxas de frequência líquida da população de 15 a 17 anos no Ensino Médio, passando de 24,1\% em 1996 para 48\%, em 2007 (no Sudeste essa taxa passou de $31,6 \%$ para $58,7 \%$ ). ${ }^{3}$ Com relação à Educação Superior, as taxas de frequência líquida da população de 18 a 24 anos passaram de 5,8\% em 1996 para 13\% em 2007 (no Sudeste as taxas passaram de 7,3\% para $16,3 \%$ no mesmo período), uma variação percentual significativa, de 123,3\%, embora aquém do desejado, uma vez que o PNE (Plano Nacional de Educação) estipulou essa taxa em 30\% para 2011.

A duplicação da taxa de frequência líquida da população de 18 a 24 anos no Ensino Superior reflete a relativa pressão para o acesso a esse nível de ensino pela população de baixa renda. Tal condição parece se refletir diretamente no movimento pela busca de alternativas para superar tais obstáculos. Segundo Carvalho et alii (2006), no início do século XXI já existiam cerca de dois mil cursos pré-vestibulares comunitários em todo o Brasil, abrangendo um universo próximo à marca dos 100 mil estudantes. 
No contexto dessas alterações, registra-se que $91,20 \%$ dos alunos que ingressaram no vestibular do Cederj em 2004 eram provenientes de famílias com renda per capita inferior a dois salários mínimos, justificando a política pública de interiorização do Ensino Superior no Estado do Rio de Janeiro através do Consórcio CEDERJ, atingindo os grotões fluminenses e permitindo a essa população o acesso à educação de qualidade. Deve-se registrar ainda que o Governo do Estado do Rio de Janeiro buscou, ao implementar o Cederj com ênfase nas licenciaturas, enfrentar a crescente diminuição dos quadros docentes nas áreas, principalmente de Matemática, Física, Química e Biologia com vistas à melhoria do Ensino Fundamental e Médio.

No quadro recente da busca pela ampliação do acesso ao nível superior, merece atenção o aumento expressivo registrado na adesão à educação a distância no país. O Censo da Educação Superior de 2008, divulgado pelo Ministério da Educação em novembro de 2009, aponta que as matrículas em cursos superiores na modalidade educação a distância cresceram 96,9\% de 2007 a 2008. Ao todo, 727.961 universitários aderiram ao Ensino Superior não presencial. Em 2008, 115 instituições ofereceram cursos dessa modalidade - 18 a mais do que em 2007 -, fazendo com que as matrículas da educação a distância já correspondam a $14 \%$ da oferta de Ensino Superior no país.

Em 2008, havia 5.080.056 alunos matriculados em cursos superiores no Brasil, $4,1 \%$ a mais do que em 2007. Informações do referido censo revelam, porém, que na educação presencial o setor privado absorve a maior parte dos alunos, respondendo por $74,9 \%$ dos alunos, enquanto $25,1 \%$ estudam em instituições públicas, apesar da expansão do número de vagas ocorrida nas universidades públicas nos últimos anos, com a criação de cursos noturnos e, recentemente, com o surgimento de campus no interior dos estados, em virtude do Reuni, programa do Governo Federal via Ministério da Educação . ${ }^{4}$

Contribui para o reforço desse quadro a iniciativa do Governo Federal de criação do Prouni (Programa Universidade para Todos). Com significativo impacto na população com renda per capita familiar até três salários mínimos, esse programa, criado em 2004, concede bolsas de estudos em instituições de ensino superior privadas. Nelas o número de vagas ociosas é significativamente alto, correspondendo a $90 \%$ das vagas não preenchidas no país. O Prouni, que exige como pré-requisito o Enem (Exame Nacional do Ensino Médio), contemplou, em 2009, 396.000 bolsistas em 1.399 instituições particulares. Ao atender à demanda represada de acesso ao Ensino Superior, entre os desafios postos ao Governo Federal cabe acompanhar e avaliar a qualidade desses cursos.

A partir deste rápido esboço acerca das recentes alterações observadas na dinâmica educacional brasileira, consideramos pertinente avaliar os méritos, as condições de efetiva realização, as possibilidades e os limites de iniciativas que busquem estender aos segmentos de menor poder aquisitivo da população o direito real de usufruir de uma formação de qualidade no nível superior. Destacamos, assim, que nossa perspectiva não é considerar o Pré-Vestibular Social - entre as demais iniciativas vigentes - um mero dispositivo para alterar os índices estatísticos relativos à escolaridade no país. Ao contrário, interessa-nos avaliar os avanços realizados e os desafios ainda encontrados para que o poder público possa, junto a outras medidas, assumir e aprofundar sua responsabilidade no processo de democratização do acesso ao ensino de qualidade e no enfrentamento tanto das situações de exclusão quanto daquelas que tendem a uma inclusão subordinada, de baixa qualidade, que não guarda compromisso com o princípio de emancipação dos sujeitos sociais.

\section{O Programa Pré-Vestibular Social - resposta a uma demanda}

No contexto das contradições sociais expressas no sistema educacional brasileiro, o Pré-Vestibular Social responde a uma demanda legítima dos segmentos economicamente menos favorecidos da população, reconhecendo a necessidade e o mérito de uma ação pública nessa área. Afinal, apesar da falta de estímulo e recursos, segmentos das camadas mais desprovidas já se organizavam no sentido de buscar alternativas para superar as deficiências do ensino público, visando a ter acesso à universidade pública, tal como dinamizado pelo Pré-Vestibular de Negros e Carentes (NASCIMENTO ET ALII, 2004), por exemplo. Assim, 
o Pré-Vestibular Social da Fundação CECIERJ procura cumprir uma importante função no contexto educacional do estado do Rio de Janeiro, buscando aperfeiçoar-se como um programa sob a responsabilidade do poder público que produza resultados em seu âmbito de atuação. Para Wanderley de Souza (2009), o PVS é um dos programas voltados para a complementação da formação dos jovens brasileiros que frequentam escolas públicas, sobretudo aqueles com maiores dificuldades e provenientes de famílias com menor renda. Nesse sentido, esse autor entende o programa como uma ação de curto prazo com o objetivo de superar as deficiências educacionais da sociedade brasileira acima mencionadas.

Deve ser destacado que se trata de um programa gratuito que oferece os conteúdos básicos das disciplinas e de informações relacionadas aos vestibulares. Desta maneira, o Estado do Rio de Janeiro busca facilitar o acesso por mérito ao ensino superior, como preceitua o art. 208, V, da Constituição da República, dando aos alunos condições de disputar o vestibular de qualquer instituição, e não somente o do Consórcio CEDERJ.

Esse programa público partilha da mesma filosofia que levou o Governo do Estado do Rio de Janeiro a instituir a Fundação CEDERJ e o Consórcio Cederj. $\mathrm{Na}$ criação desses programas $e$ instituições partiuse do pressuposto de que o acesso à universidade amplia as possibilidades de inserção no mercado de trabalho e contribui, de modo geral, para a melhoria das condições de vida. Considera-se ainda que a universidade é um espaço fundamental de transmissão de valores e ideias, desdobrando-se em ganhos posteriores. Assim, essa experiência visa ampliar os horizontes/perspectivas de cidadania dos segmentos mais pauperizados da população.

\subsection{Trajetória estruturante e metodologia do curso}

O Pré-Vestibular Social iniciou suas atividades em 2003, oferecendo aulas de Língua Portuguesa e Matemática com três horas cada, aos sábados. Na medida em que apresentou resultados e, por conseguinte, conquistou espaço institucional e recursos orçamentários $^{5}$, incluiu progressivamente novas disciplinas.
Em 2004, incorporou as disciplinas de Biologia e Física; em 2005, as disciplinas de Química e Geografia; em 2006, História; e, em 2007, Redação. Hoje, das disciplinas exigidas nos vestibulares, somente não é oferecida a língua estrangeira. Estão disponíveis duas modalidades do curso quanto à duração e ao ritmo: 0 extensivo, que ocorre de março a dezembro, e o intensivo, de junho a dezembro. Um polo padrão do PVS engloba seis turmas de 60 alunos, totalizando 360 vagas, e 8 tutores para as 8 disciplinas.

Em 90\% dos 49 polos existentes em 2010, com o objetivo de atingir o público que trabalha durante a semana, as aulas são oferecidas aos sábados das 8 às $17 \mathrm{~h}$, com uma hora de aula de cada disciplina. Por ser centrado em um único dia, evita os altos custos do transporte para os alunos. Em $10 \%$ dos polos, as aulas ocorrem duas vezes por semana, à tarde.

Todo o material didático é oferecido aos alunos gratuitamente; são dois livros de cada disciplina ao longo do curso. Dos 49 polos, os 37 que estão abrigados em dependências de escolas estaduais e os 6 que funcionam em escolas municipais oferecem almoço aos alunos aos sábados, conforme estabelecem os convênios com a Secretaria de Estado de Educação e as prefeituras municipais, respectivamente. A alimentação disponibilizada é um fator importante na frequência $e$ permanência dos alunos.

Para dar suporte à dinâmica de ensino-aprendizagem, um serviço tira-dúvidas sobre o material didático é realizado por tutores de todas as disciplinas, usando linhas 0800 que funcionam de segunda a sexta-feira, das $8 \mathrm{~h}$ às $18 \mathrm{~h}$. Ao longo do curso, são realizados simulados presenciais e a distância e disponibilizados exercícios online no site www.pvs.cederj.edu.br.

Em 2009, foi implementado um sistema de orientação acadêmica, em que cada tutor é designado para acompanhar um grupo de alunos, independente de vínculo de turma, a fim de que, através de contatos diretos, fora da sala de aula, por e-mail e através de sites de relacionamento, o estudante possa ser assistido de forma mais direta, tratando de frequência ao curso, disponibilização de exercícios complementares, informações sobre carreiras, vestibulares, isenções de taxa etc. A inscrição gratuita no vestibular do CEDERJ para alunos do PVS que 
tiveram ao menos $75 \%$ de frequência constitui-se em outra estratégia de inclusão.

Dessa maneira, o curso pode ser caracterizado por utilizar uma metodologia de ensino presencial, com somente uma hora de aula semanal de cada disciplina, mas contando com a utilização intensiva de tecnologias de ensino a distância (EAD), como material didático especialmente preparado, tutoria a distância, simulados, exercícios e feedback on line para os alunos. As dificuldades apresentadas por parcela dos alunos no acesso a computador (Tabela 1) são supridas pelos horários especiais criados pelos diretores de polos do CEDERJ para o seu atendimento.

Tabela 1: PVS 2009 - Alunos - Acesso a computador

\begin{tabular}{|c|c|c|}
\hline Onde utiliza o computador? & Quantidade & $\%$ \\
\hline Em casa & 7.352 & $47 \%$ \\
\hline Lan-house & 4.543 & $29 \%$ \\
\hline Casa de parentes / amigos & 1.474 & $9 \%$ \\
\hline No trabalho & 889 & $6 \%$ \\
\hline $\mathrm{Na}$ escola & 836 & $5 \%$ \\
\hline Não usa & 650 & $4 \%$ \\
\hline Total & 15.744 & $100 \%$ \\
\hline
\end{tabular}

Fonte: PVS/Banco de Dados de Alunos, 2009.

\subsection{Perfil da população atendida e dinâmica de funcionamento}

Como mostra a Tabela 2, entre 2003 e 2009 foi gradativamente ampliado o contingente de polos criados, municípios e alunos beneficiados, acompanhando e antecipando a própria inserção do CEDERJ no interior. Houve nesse período 133.754 candidatos inscritos e passaram pelo sistema 74.302 alunos. Deve-se registrar a significativa demanda para a implementação de polos na Região Metropolitana do Rio de Janeiro e na Baixada Fluminense, bem como a elevada relação candidato/vaga nessas duas regiões.
Na seleção dos alunos beneficiados, é levada em consideração a situação socioeconômica do candidato e dos residentes no mesmo domicílio. No processo seletivo em andamento (2010), os candidatos que apresentam renda per capita familiar superior a $\mathrm{R} \$ 630,00$ (1,5 salário mínimo em valores de $2008^{6}$ ) podem frequentar o curso somente quando há sobra de vagas. Compõe também o processo seletivo a apresentação de um projeto acadêmico consolidado em um texto em que o candidato aborda a sua vida como estudante e tece considerações sobre os seus planos.

Tabela 2: PVS 2003-2009

\begin{tabular}{|l|r|r|r|r|}
\hline Ano & Polos & & & \\
\hline 2003 & 18 & 18 & 8.897 & 4.818 \\
\hline 2004 & 19 & 19 & 10.574 & 7.218 \\
\hline 2005 & 27 & 23 & 19.599 & 9.400 \\
\hline 2006 & 32 & 25 & 13.474 & 9.156 \\
\hline 2007 & 37 & 27 & 23.460 & 13.515 \\
\hline 2008 & 42 & 32 & 28.040 & 14.451 \\
\hline 2009 & 44 & 34 & 29.710 & 15.744 \\
\hline 2010 & 49 & 37 & & $*$ \\
\hline TOTAIS & & & $\mathbf{1 3 3 . 7 5 4}$ & $\mathbf{7 4 . 3 0 2}$ \\
\hline
\end{tabular}

Fonte: PVS/Banco de Dados de Alunos, 2003-2009.

* Processo seletivo em andamento. 
Como demonstra a Tabela 3, 86\% dos alunos apresentam renda per capita familiar igual ou inferior a $\mathrm{R} \$ 630,00$.

Aqueles que apresentam renda superior são provenientes de municípios do interior que se inscrevem no curso por não haver outras opções disponíveis na região e/ou porque a relação candidato/vaga no PVS permite o seu ingresso.

Mais de um terço dos alunos que ingressam no curso nunca teve aulas de Física e Química, maté-

Tabela 3: PVS 2009 - Alunos - Renda per capita familiar

\begin{tabular}{|c|c|c|}
\hline Faixa de renda per capita & $\begin{array}{l}\text { Número de alunos extensivo } \\
\text { e intensivo (2009) }\end{array}$ & $\%$ \\
\hline$<=\mathrm{R} \$ 207$ & 4.136 & $26 \%$ \\
\hline$>\mathrm{R} \$ 207,00 \mathrm{e}<=\mathrm{R} \$ 415,00$ & 6.423 & $41 \%$ \\
\hline$>\mathrm{R} \$ 415,00$ e $<=\mathrm{R} \$ 630,00$ & 3.060 & $19 \%$ \\
\hline$>\mathrm{R} \$ 630,00$ & 2.125 & $13 \%$ \\
\hline Total & 15.744 & $100 \%$ \\
\hline
\end{tabular}

Fonte: PVS/Banco de Dados de Alunos, 2009.

rias requisitadas nos vestibulares. Isso ocorre porque são egressos de modalidades de Ensino Médio, tais como Técnico ou de Formação de Professores (Tabela 4), ou simplesmente devido à inexistência de professores dessas disciplinas durante a realização do Ensino Médio. Esse fato impõe dificuldades adicionais aos tutores que buscam, no pouco tempo disponível, suprir as deficiências de formação dos alunos. Frequentam o curso alunos de todas as faixas etárias, havendo concentração entre os jovens até 24 anos, como demonstra a Tabela 5.

As turmas são compostas de acordo com as faixas etárias, procurando-se agrupar os mais jovens e os mais velhos em turmas separadas. Esse procedimento tem facilitado o trabalho dos professores em sala e agradado aos alunos, por evitar "conflitos de gerações".

Tabela 4: PVS 2009 - Alunos - Modalidade de Ensino

\begin{tabular}{|c|c|c|}
\hline Modalidade de ensino & $\begin{array}{l}\text { Número de alunos extensivo } \\
\text { e intensivo (2009) }\end{array}$ & $\%$ \\
\hline Ensino Médio regular & 9.850 & $63 \%$ \\
\hline Formação de Professores & 2.109 & $13 \%$ \\
\hline Supletivo & 2.016 & $13 \%$ \\
\hline Técnico & 1.769 & $11 \%$ \\
\hline Total & 15.744 & $100 \%$ \\
\hline
\end{tabular}

Fonte: PVS/Banco de Dados de Alunos, 2009.

Tabela 5: PVS 2009 - Alunos - Faixa etária

\begin{tabular}{|c|c|c|}
\hline Faixa de idade & $\begin{array}{l}\text { Número de alunos extensivo } \\
\text { e intensivo (2009) }\end{array}$ & $\%$ \\
\hline$<18$ & 3.482 & $22 \%$ \\
\hline Entre 18 a 24 & 6.300 & $40 \%$ \\
\hline Entre 25 a 30 & 2.047 & $13 \%$ \\
\hline Entre 31 a 40 & 2.335 & $15 \%$ \\
\hline$>40$ & 1.580 & $10 \%$ \\
\hline \multicolumn{2}{|c|}{ Total } & $100 \%$ \\
\hline
\end{tabular}

Fonte: PVS/Banco de Dados de Alunos, 2009. 


\subsection{Dinâmica de funcionamento do curso e resultados}

Em termos gerenciais, o curso conta com uma diretora e três coordenadores executivos responsáveis por toda a logística de funcionamento: implementação de polos, manutenção do sistema de comunicação com os coordenadores de disciplinas, tutores, alunos e diretores de polo/escolas, transporte de tutores, folha de pagamento, grade horária do curso, administração dos bancos de alunos e tutores. Conta ainda com 19 coordenadores de disciplinas, um administrador do site $e$ de sistemas on line vinculados à internet, uma designer gráfica responsável pela editoração dos 16 livros, uma assistente social e três assistentes administrativos. A comunicação da direção com os tutores se dá preferencialmente por e-mail, com orientaçóes semanais a todos os tutores, e pelo SisPVS - a plataforma digital que abriga os diários de classe online, o Sistema de Orientação Acadêmica e os relatórios semanais de todos os tutores e dos tutores representantes etc. Sem o uso cotidiano e intensivo da internet e dos sistemas on line - criados ao longo da existência do PVS abrigado numa instituição de EAD como é o CEDERJ - não seria possível gerenciar um projeto dessa magnitude.

Para atender aos 15.744 alunos, o Programa contou, em 2009, com 370 tutores, cujo ingresso se deu por uma disputada e rigorosa seleção pública com prova de conteúdo e didática. Além de profissionais formados, podem se inscrever alunos de graduação.

O grupo de tutores constitui a mola mestra, ou melhor, a joia do projeto, pois todas as atividades acadêmicas e gerenciais do dia a dia no polo (49 unidades em 37 municípios em 2010) dependem do tutor. Do ponto de vista gerencial, um dos oito componentes do grupo de tutores de um polo - o tutor representante -, além de ministrar a mesma carga horária, coordena as atividades e toma outras providências, como o repasse das informações da direção, avisos sobre inscrições para isenção de taxas de vestibulares, realocação de salas de aula, supervisão da alimentação, controle de frequência dos tutores e outras eventualidades de um dia de aula. Todo tutor deve permanecer no polo por oito horas no sábado, independentemente do número de horas-aula (4 ou 6) ministradas, com uma hora de intervalo para o almoço.
O tutor de disciplina tem como obrigação realizar o controle de frequência dos alunos e registrá-la nos diários de classe online, inserir na plataforma seu relatório semanal sobre o andamento da disciplina $e$ outras ocorrências do dia de aula. Deve ainda registrar seu plano de aula, assim como inserir no Sistema de Orientação Acadêmica os contatos presenciais ou virtuais realizados com seus orientandos. A experiência didática no Pré-Vestibular Social é supervisionada semanalmente pelos coordenadores das disciplinas $e$ sistematicamente controlada pela direção geral. Por esses motivos, muitas instituições reconhecem este trabalho como estágio didático obrigatório e vários tutores ingressam no curso para obter a comprovação oficial dessa experiência.

Os tutores são avaliados pelos alunos, o que conta para a renovação anual de sua bolsa, não somente como docentes na sala de aula mas também como orientadores nas dificuldades para definir uma carreira ou para permanecer no curso. O processo de avaliação dos tutores pelos alunos, pelas coordenações das disciplinas e pela direção é reconhecido como um elemento vital para a manutenção da qualidade do curso.

Pelas características da população atendida, um dos desafios colocados ao curso é a evasão. Segundo Bastos (2009), nos primeiros meses o índice de comparecimento ao curso é bastante alto; no entanto, observa-se um processo de evasão à medida que os exames vestibulares ocorrem - a exemplo do $1^{\circ}$ exame de qualificação da UERJ, realizado em junho. O desempenho insatisfatório no meio do ano, para quem ainda não está bem preparado, acaba por desestimular muitos alunos.

Não obstante, os alunos do PVS têm disputado vagas em universidades públicas e privadas $e$, com o aprimoramento que adquirem em Língua Portuguesa, Redação e Matemática, têm também conquistado aprovações em concursos públicos, principalmente nas prefeituras municipais no interior do estado.

Em termos de desempenho dos alunos, podemos afirmar que o PVS faz diferença no interior do estado e contribui para que o CEDERJ cumpra sua missão de interiorizar o acesso ao ensino superior. 
O PVS demonstra sua efetiva contribuição para que alunos carentes nessas regiões tenham acesso ao ensino superior público, gratuito e de qualidade. No Vestibular 2009-2 do Consórcio Cederj, realizado em julho passado, um total de 521 alunos - $20 \%$ dos que realizaram as provas - ocupou as vagas da graduação.

A contribuição do Pré-Vestibular Social pode ser demonstrada pelos dados que seguem:

- No curso de Licenciatura em Ciências Biológicas, de responsabilidade da UFRJ e da UENF, em 12 municípios de diferentes regiões do estado, a taxa de ocupação das vagas da graduação pelos alunos do PréVestibular Social foi superior a $20 \%$, com destaque para Três Rios, com $42 \%$.

- Em Saquarema, dos alunos do curso de Turismo, de responsabilidade da UFRRJ, $35 \%$ são provenientes do PVS.

- No curso de Tecnologia em Sistemas de Computação, também de responsabilidade da UFRRJ, 29\% das vagas foram ocupadas pelos alunos locais de Três Rios e $23 \%$ pelos de Angra dos Reis.

- Em São Fidélis, 33\% dos alunos do PVS ocuparam as vagas de Química da UENF; em Itaperuna, $20 \%$ ocuparam as vagas de Administração, da UFRRJ; em Paracambi, 19\% ocuparam as vagas de Física, da UFRJ.

- Na Baixada Fluminense, onde a relação candidato/vaga é alta, sobressaem os municípios de Belford Roxo, com $25 \%$ de taxa de aprovação dos alunos do PVS no curso de Pedagogia, da UERJ; Duque de Caxias e Nova Iguaçu destacam-se com $22 \%$ e $27 \%$ no curso de Ciências Biológicas, da UFRJ.

O esforço e as realizações dos alunos do Pré-Vestibular Social se tornam mais valiosos se considerarmos que o critério de ingresso no curso preparatório é a carência socioeconômica e que o vestibular tem como referência o mérito acadêmico. Apenas $10 \%$ dos aprovados se valeram da Lei de Cotas.

São registradas também inúmeras aprovações em cursos presenciais de universidades públicas como UFF, UERJ e UFRJ, conforme constam em depoimentos de alunos no Hall dos Aprovados (www.pvs. cederj.edu.br/hall).

\section{Considerações finais}

No cenário atual de economia globalizada, o mercado de trabalho impõe uma formação continuada e rigorosa, com maior valorização do trabalho intelectual e das capacidades inovadoras e integradoras que ele permite.

Entendemos que o desenvolvimento de ações educativas complementares que visem favorecer a permanência e a qualidade da aprendizagem de alunos de baixa renda, em situação de vulnerabilidade ou socialmente excluídos, inclusive do sistema educacional, é de fundamental importância como contribuição para uma maior inclusão dos segmentos mais pobres da população, sobretudo em instituições como as universidades públicas, que historicamente têm sido elitizadas, especialmente, em bacharelados profissionais.

A importância do Pré-Vestibular Social se confirma por abrir oportunidades para que pessoas do interior $e$ de baixa renda possam ter o seu valor revelado, contribuindo para as suas comunidades locais por meio das chances que o Ensino Superior de qualidade oferece.

A despeito da relevância do programa e de seus resultados, cabe destacar algumas alternativas para sua ampliação e melhoria que podem ser incorporadas para o pleno desenvolvimento institucional do Pré-Vestibular Social.

Considerando que a procura por vagas no PVS tem sido cada vez maior, é necessária a ampliação de polos em diferentes municípios e a melhoria da infraestrutura nos já existentes, haja vista que a maior reclamação dos alunos reside nas condições das salas de aulas e de banheiros das escolas. Por outro lado, apesar dos bons índices de aprovação obtidos pelo PVS, deve-se incentivar continuamente o aperfeiçoamento de professores e criar estratégias/incentivos que garantam a qualidade do curso.

Almeja-se a melhora na capacitação tanto de alunos como de professores na área de informática, através de cursos de extensão a distância, assim como na área de idiomas. Isso pode se traduzir em maior qualificação e inclusão social, considerando que hoje quem tem acesso a uma segunda língua tem privilégios no mercado de trabalho, na transmissão de ideias e valores e possibilidades de desenvolvimentos posteriores. Além disso, o ensino a distância requer habilida- 
de em uma segunda língua (inglês) pelo menos em caráter instrumental, para que alunos e professores possam melhor utilizar a informática como veículo de aprendizagem. A implementação da disciplina de língua estrangeira (inglês) com metodologia EAD é uma meta a curto prazo do curso.

Encontra-se também entre as preocupações ampliar o leque de ofertas culturais aos alunos e professores, através de acesso ao teatro e a outros eventos, não só para melhorar o nível cultural destes mas também como estratégia de criar uma nova sociabilidade entre alunos e tutores do PVS, possibilitando a fixação dos últimos e evitando a evasão dos primeiros.

No cotidiano do PVS permanecem os desafios na área de Educação Especial, para a inclusão de alunos de baixa renda deficientes visuais e auditivos, haja vista os custos elevados para a transformação do material didático em braille e a contratação de especialistas em linguagem de sinais (intérprete de libras) para diversos polos.

De toda forma, não se pode negar que, apesar do sucesso do programa (ainda restrito ao estado do Rio de Janeiro) considerando o seu alcance em termos do número de pessoas atendidas e regiões, permanece a necessidade de um grande investimento a ser feito pelo poder público na área de educação em todos os níveis para recuperar o déficit educacional, superar a baixa qualidade do ensino e o crescente abismo entre a educação privada e a pública, que revelam a dimensão que o fenômeno da exclusão em nosso país alcança. Entendemos que o estado não pode abdicar de seu papel na garantia desse direito básico de cidadania, sob pena de ter que arcar com graves consequências para a formação ética, política, social e cultural da população brasileira.

\section{Notas}

${ }^{1}$ O Governo Anthony Garotinho (1999-2002) propôs e instituiu o Consórcio CEDERJ - UERJ, UENF, UFF, UFRJ, RURAL e UNIRIO, em 2001, com a finalidade de propiciar o acesso ao Ensino Superior público gratuito, de qualidade, através da metodologia a distância, aos moradores do interior do estado. Em 2003, o Governo Rosa Garotinho (2003-2006) implantou o Pré-Vestibular Social.

${ }^{2}$ Conforme os autores, "apenas $47 \%$ dos jovens entre 15 a 17 anos cursam esse nível; $35 \%$ dos matriculados têm de 18 a 24 anos; os demais, 25 anos ou mais de idade" (idem, p. 7).

${ }^{3}$ Cor, nível de renda e local de moradia do jovem são variáveis que interferem nas oportunidades de acesso.

4 "O Programa de Apoio a Planos de Reestruturação e Expansão das Universidades Federais Brasileiras (REUNI) é uma das ações integrantes do Plano de Desenvolvimento da Educação (PDE) e foi instituído em reconhecimento ao papel estratégico das universidades - em especial do setor público - para o desenvolvimento econômico e social. Com o REUNI, o Governo Federal adotou uma série de medidas a fim de retomar o crescimento do Ensino Superior público, criando um programa multidimensional e, ao mesmo tempo, acadêmico, político e estratégico. Os efeitos da iniciativa podem ser percebidos pelos expressivos números da expansão, iniciada em 2008 e prevista para concluir-se em 2012, e pela oportunidade que representa para a reestruturação acadêmica com inovação que significará, em curto prazo, uma verdadeira revolução na educação superior pública do país." Disponível em: http://reuni.mec.gov.br. Acesso em 10/11/2009.

${ }^{5}$ O PVS conta com recursos orçamentários do Fundo de Combate à Pobreza do Estado do Rio de Janeiro.

${ }^{6}$ Em 2008, o salário mínimo correspondia a $\mathrm{R} \$ 415,00$. 


\section{Referências bibliográficas}

BASTOS, M. D. F. Cederj: 12 mil vagas em pré-vestibular. Folha Dirigida, 22-28 jan. 2009. Caderno de Educação

BRASIL. Constituição da República Federativa do Brasil, promulgada em 5 de outubro de 1988. São Paulo: Saraiva, 2003.

CARVALHO, José Carmelo Braz de et al. Cursos pré-vestibulares comunitários: espaços de mediações pedagógicas. Cadernos de Pesquisa, São Paulo, v. 36, n. 128, maio/ago. 2006. Disponível em: <http:/www. scielo.br>. Acesso em: 08 abr. 2010.

CARVALHO, J. M.; GRIN, M. Universidade pública: elitista? Ciência Hoje, Rio de Janeiro, v. 34, n. 203, , p. 16-20, abr. 2004.

CASTRO, J. A.; AQUINO, L. M. C.; ANDRADE, C. C. (Org.) Juventude e políticas sociais no Brasil. Brasília: Ipea, 2009.

CRUZ, C. H. B. Universidade pública: o mito do elitismo. O Estado de S. Paulo, São Paulo, Espaço Aberto, 18 jan. 2004.

DUARTE FILHO, O. B. Inclusão social na universidade brasileira: princípios e alternativas. Disponívelem: <http:// www.sbpcnet.org.br/livro/57ra/programas/CONF_SIMP/ textos >. Acesso em: 14 out. 2009.

BRASIL. MEC/INEP. Inep divulga os resultados do Enem 2006 por UF e escola. Disponível em: <http:// www.inep.gov.br/imprensa/noticias/enem/news07_02. htm > . Acesso em: 20 fev. 2010.

IBRASIL. MEC/INEP. Divulgado o Censo da Educação Superior 2008. Disponível em: <http://www.inep. gov.br/imprensa/noticias/censo/superior/news09_05. htm >. Acesso em: 20 fev. 2010.

KUENZER, A. Z. Exclusão includente e inclusão excludente: a nova forma de dualidade estrutural que objetiva as novas relações entre educação e trabalho. In: SAVIANI, D.; SANFELICE, J. L.; LOMBARDI, J. C. (Org.). Capitalismo, trabalho e educação. 3. ed. Campinas: Autores Associados, 2005. p. 77-96.
MARTINS, J. S. Exclusão e a nova desigualdade. São Paulo: Paulus, 1997.

NASCIMENTO, A.; IGNACIO, J.; PINHEIRO, F. Das ações afirmativas dos movimentos sociais às políticas públicas de ação afirmativa. O Público e o Privado, n. 3, janeiro-junho de 2004.

NEVES, C. E. B.; RAIZER, L.; FACHINETTO, R. F. Acesso, expansão e equidade na educação superior: novos desafios para a política educacional brasileira. Sociologias, Porto Alegre, v. 17, 2007, p. 124-157.

OLIVEIRA, L. Os excluídos existem? Notas sobre a elaboração de um novo conceito. Revista Brasileira de Ciências Sociais, São Paulo, ano 12, n. 33, 1997.

SOUZA, W. O sucesso do Pré-Vestibular Social da Fundação Cecierj. Monitor Mercantil, Rio de Janeiro, Opinião. Disponível em: < http://monitormercantil. com.br/mostranoticia.php?id=68923 $>$. Acesso em: 13 out. 2009.

UFRJ. Comissãode Vestibular (2010). Disponívelem: <http://www.acessograduacao.ufrj.br/Downloads/ Concurso_2007_SocioCultural_Classificados. pdf $>\quad e^{<} \quad$ http://www.acessograduacao.ufrj.br/ Downloads/Concurso_2007_SocioCultural_Geral_ Inscritos.pdf $>$. Acesso em: 19 fev. 2010. 
